[8] Wong CK, Gao W, Stewart RA, et al. aVR ST elevation: an important but neglected sign in ST elevation acute myocardial infarction. Eur Heart J 2010;31:1845-53.

[9] Wong CK, Gao W, Stewart RA, French JK, Aylward PE, White HD, 2011. The prognostic meaning of the full spectrum aVR ST segment changes in acute myocardial infarction. Eur Heart J, doi:10.1093/eurheart/ehr301 [Electronic publication ahead of print].

[10] Wagner GS, MacFarlene P, Wellens $\mathrm{H}$, et al. AHA/ACCF/HRS recommendations for the standardization and interpretation of the electrocardiogram Part VI Acute ischemia/infarction: a scientific statement from the American Heart Association Electrocardiography and Arrhythmias Committee, Council on Clinical Cardiology; the American College of Cardiology Foundation; and the Heart Rhythm Society: endorsed by the International Society for Computerized Electrocardiology. J Am Coll Cardiol 2009;17(53):1003-11.

[11] Bond RR, Finlay DD, Nugent CD, Moore G. tool for processing and visualizing body surface potential maps. J Electrocardiol 2010;43(6):560-5.

[12] Robinson M, Bannister C, Reddiar R, Gray H, Curzen N. Detecting transient myocardial ischemia in the context of acute coronary syndrome in the emergency department: delta map analysis of body electrocardiographic surface mapping. Circ Cardiovasc Imaging 2009 May;2(3):e17-9.

[13] Owens C, Navarro C, McClelland A, et al. Improved detection of acute myocardial infarction using a diagnostic algorithm based on calculated epicardial potentials. Int J Cardiol 2006 Aug 10;111(2):292-301.

[14] Owens C, McClelland A, Walsh S, Smith B, Adgey J. electrocardiogram for diagnosis of acute myocardial infarction. Am J Cardiol 2008 Aug 1;102(3):257-65.

[15] Ornato JP, Menown IB, Peberdy MA, et al. myocardial infarction. Am J Emerg Med 2009 Sep;27(7):779-84.

[16] Neill J, Owens C, Harbinson M, Adgey J. Early detection of acute posterior myocardial infarction using body surface mapping and SPECT scanning. Coron Artery Dis 2010 Nov;21(7):420-7.

[17] Daly MJ, McCann CJ, Owens CG, Harbinson MT, Adgey JA. at presentation. J Electrocardiol 2011;44:432-8.

[18] Scott PJ, Navarro C, Stevenson M, et al. elevation myocardial infarction.J Electrocardiol 2011;44:425-31.

\title{
Association between vitamin D deficiency and heart failure in the elderly
}

\author{
Ángela Ruiz de Temiño ${ }^{a}$, Judith Gil a, Teresa Pérez ${ }^{b}$, Marta González ${ }^{a}$, Mónica Pineda a , \\ Antonio Dueñas-Laita ${ }^{c}$, José Luis Pérez-Castrillón ${ }^{\mathrm{a}, *}$ \\ a Internal Medicine Service, Hospital Universitario Río Hortega, Valladolid, Spain

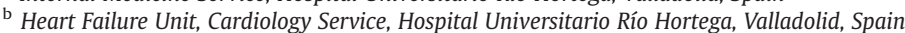 \\ c Clinical Toxicology Unit, Hospital Universitario Río Hortega, Valladolid, Spain
}

\section{A R T I C L E I N F O}

\section{Article history:}

Received 3 August 2011

Accepted 17 August 2011

Available online 13 September 2011

\section{Keywords:}

Vitamin D

Heart failure

Elderly

\section{Dear Sir,}

Vitamin D (25-OH-vitamin D) is a hormone which acts on the calcium-phosphorus metabolism and also has extraskeletal effects. In the cardiovascular system, it regulates the renin-angiotensinaldosterone system (RAAS), inhibits vascular smooth muscle proliferation, and suppresses cardiac hypertrophy and hypercontractility [1].

We assessed the relationship between vitamin D deficiency and heart failure (HF) in an elderly population. We carried out a prospective case-control study in the Internal Medicine Department, Rio Hortega Hospital, Valladolid in 2010. Twenty-five patients were diagnosed with HF and 19 were institutionalized controls with no history of cardiovascular disease (CVD). The age of patients and control group was similar ( $83 \pm 7$ years vs. $85 \pm 8$ years, $p>0.05$ ). The sex distribution don't show differences. HF was diagnosed according to clinical and laboratory criteria (B-type natriuretic peptide $>400 \mathrm{pg} / \mathrm{mL}$ ). Vitamin D insufficiency was defined as levels $<20 \mathrm{ng} / \mathrm{ml}$ and deficiency as $<10 \mathrm{ng} / \mathrm{ml}$. Two-dimensional echocardiography evaluated systolic and diastolic function, pulmonary artery systolic pressure (PASP), atrial fibrillation and valvular disease in the HF group.

Patients with HF had lower vitamin D levels than controls (8.47 \pm 4.85 vs. $17.13 \pm 6.44, p=0.0001$ ) (Fig. 1 ) and $78.3 \%$ had vitamin $D$

\footnotetext{
* Corresponding author at: Servicio de Medicina Interna, Hospital Río Hortega, C/ Dulzaina № 2, 47012-Valladolid, Spain. Tel.: + 34983420400 ; fax: + 34983331566.

E-mail address: castrv@terra.es (J.L. Pérez-Castrillón).
}

deficiency, compared with $5.3 \%$ of controls . Vitamin D levels remained significantly higher in the HF group $(p=0.009)$, after stratification for institutionalization. Intact parathormone (iPTH) levels were also significantly higher in patients with $\mathrm{HF}(p=0.0001)$.

Echocardiography showed a mean ejection fraction (EF) of $54 \% \pm 15$ and $45 \%$ of patients had systolic dysfunction (severe in $5 \%$ ). The diastolic pattern could not be estimated in enough patients to establish a relationship between vitamin D deficiency and HF with preserved EF, because $40 \%$ of patients had atrial fibrillation. Seventy-two percent of patients had valvular disease and $80 \%$ had significant pulmonary hypertension (mean PASP $57 \pm 15 \mathrm{mmHg}$ ).

Recent years have provided new insight into the pathophysiology of HF. Vitamin D inhibits the RAAS, which is involved in the development of heart failure and hypertension, and reduces inflammation, thereby protecting the vascular endothelium. In addition, low levels of vitamin D favour myocardial hypertrophy. Recent studies have shown an association between an increased prevalence of CVD and vitamin D deficiency [2,3].

Our findings that patients with HF had lower vitamin D levels than controls are similar to those of other studies. Kim et al. [4] and Ameri et al. [5] found hypovitaminosis D in $81 \%$ and $90 \%$, respectively, of patients with HF. No Spanish study has previously reported this association. Ameri et al. [5] observed an increase in systolic and diastolic left ventricle diameters and volumes in patients with vitamin D deficiency. However, we found no such association, probably due to the high incidence of valvular disease and pulmonary hypertension in our sample.

Our results and those of other studies suggest a possible association between vitamin D and heart failure. However, it is unclear whether this deficit is secondary to reduced exposure to sunlight and inadequate intake in patients with HF or is a risk factor for its development. We stratified the results according to institutionalization, as these patients might be expected to have less exposure to sunlight, but patients with HF still had moresevere vitamin D deficiency, supporting the idea that this may be a risk factor for CVD [6].Further studies should analyze the potential role of vitamin $\mathrm{D}$ in the pathogenesis of CVD and the possible benefits of supplementation. 


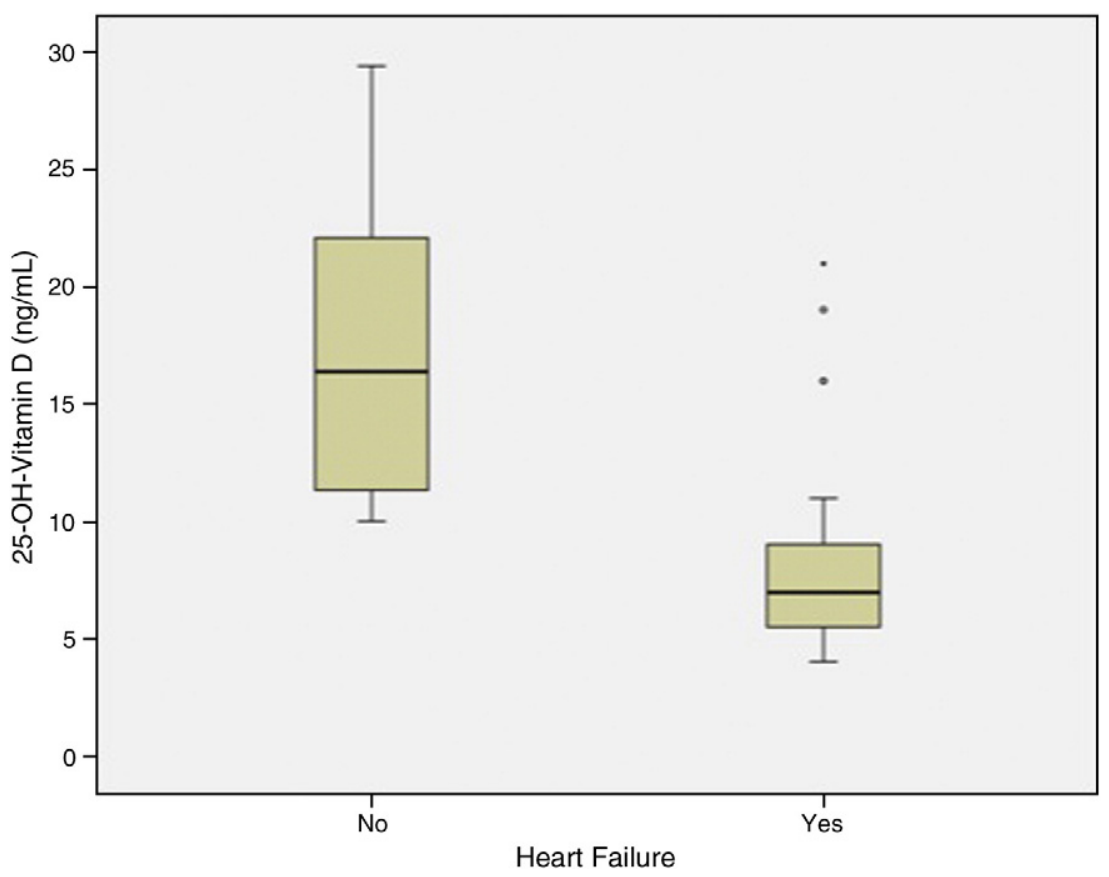

Fig. 1. Levels of vitamin D.

\section{References}

[1] Hajjar V, Depta JP, Mountis M. Does vitamin D deficiency play a role in the pathogenesis of chronic heart failure? Do supplements improve survival? Cleveland Clinic. J Med 2010;77:290-3.

[2] Pittas AG, Chung M, Trikalinos T, Mitri J, Brendel M, Patel K, et al. Systematic review: vitamin D and cardiometabolic outcomes. Ann Intern Med 2010;152:307-14.

[3] Anderson JL, May HT, Horne BD, Bair TL, Hall NL, Carlquist JF, et al. Relation of vitamin D deficiency to cardiovascular risk factors, disease status, and incident events in a general healthcare population. Am J Cardiol 2010;106:963-8.
[4] Kim DH, Sabour S, Sagar UN, Adams S, Whellan DJ. Prevalence of hipovitaminosis D in cardiovascular diseases (from the National Health and Nutrition Examination Survey 2001 to 2004). Am J Cardiol 2008;102:1540-4.

[5] Ameri P, Ronco D, Casu M, Denegri A, Bovio M, Menoni S, et al. High prevalence of vitamin D deficiency and its association with left ventricular dilation. An echocardiography study in elderly patients with chronic heart failure. Nutr Metab Cardiovasc Dis 2010;20(9):633-40.

[6] Fiscella K, Franks P. Vitamin D, race, and cardiovascular mortality: findings from a National US Sample. Ann Fam Med 2010;8:11-8.

\title{
Pigment epithelium-derived factor (PEDF) blocks advanced glycation end products (AGEs)-RAGE-induced suppression of adiponectin mRNA level in adipocytes by inhibiting NADPH oxidase-mediated oxidative stress generation
}

\author{
Sayaka Maeda ${ }^{a}$, Takanori Matsui ${ }^{\text {a }}$, Masayoshi Takeuchi ${ }^{\mathrm{b}}$, Sho-ichi Yamagishi ${ }^{\text {a,* }}$ \\ a Department of Pathophysiology and Therapeutics of Diabetic Vascular Complications, Kurume University School of Medicine, Kurume, Japan \\ ${ }^{\mathrm{b}}$ Department of Advanced Medicine, Medical Research Institute, Kanazawa Medical University, Kanazawa, Japan
}

\section{A R T I C L E I N F O}

Article history:

Received 21 July 2011

Accepted 17 August 2011

Available online 10 September 2011

Keywords:

AGEs

Adiponectin

Insulin resistance

PEDF

\footnotetext{
* Corresponding author at: Department of Pathophysiology and Therapeutics of Diabetic Vascular Complications, Kurume University School of Medicine, 67 Asahi-machi, Kurume 830-0011, Japan. Tel.: + 8194231 7873; fax: + 81942317895.

E-mail address: shoichi@med.kurume-u.ac.jp (S. Yamagishi).
}

Reactive derivatives from non-enzymatic glucose-protein condensation reactions, as well as lipids and nucleic acids exposed to reducing sugars, form a heterogeneous group of irreversible adducts called "advanced glycation end products (AGEs)" [1]. The formation and accumulation of AGEs have been known to progress at an accelerated rate under diabetes [1]. There is accumulating evidence that AGEs and their receptor RAGE interaction elicits oxidative stress generation and inflammatory reactions, thereby being involved in the pathogenesis of vascular complications in diabetes [2,3]. Recently, AGEs-RAGE axis has also been shown to play an important role in insulin resistance [4-7]. Indeed, AGEs attenuate cellular insulin sensitivity in cultured adipocytes by increasing reactive oxygen species (ROS) generation through the interaction with RAGE [5]. Further, an inhibitor of AGEs formation ameliorates insulin sensitivity in obese, type 2 diabetic mice [6]. Moreover, serum level of AGEs was reported to be one of the 